\title{
Single photon emission computed tomography in systemic lupus erythematosus with psychiatric
} symptoms

\author{
K Kodama, S Okada, T Hino, K Takabayashi, Y Nawata, Y Uchida, N Yamanouchi, \\ N Komatsu, T Ikeda, N Shinoda, A Murakami, T Sakamoto, T Sato
}

\begin{abstract}
Single photon emission computed tomography (SPECT) with $n$-isopropyl-p[123] ]iodoamphetamine (IMP) was performed on 20 patients with systemic lupus erythematosus (SLE). Fifteen of the patients showed areas of hypoperfusion. All nine patients who had florid psychiatric manifestations at the time the SPECT was performed had hypoperfusion areas. Four patients who had abnormal SPECT findings during psychiatric remission had psychiatric exacerbation one to six months after the SPECT. Four patients who had no hypoperfusion during psychiatric remission had good psychiatric prognoses. Two patients who had no history of psychiatric abnormality but showed hypoperfusion had psychiatric manifestations one month after the SPECT. The IMP-SPECT may be useful as a biological marker that represents the activity of cerebral involvement underlying psychiatric manifestations and the presence of subclinical CNS involvement.
\end{abstract}

(F Neurol Neurosurg Psychiatry 1995;58:307-311)

Neuropsychiatry,

School of Medicine,

Japan

K Kodama

S Okada

T Hino

N Yamanouchi

N Komatsu

T Ikeda

N Shinoda

A Murakami

T Sakamoto

T Sato

The Second

Department of

Internal Medicine,

School of Medicine,

Chiba University,

Japan

K Takabayashi

Y Nawata

Department of

Radiology, School of

Medicine, Chiba

University, Japan

Y Uchida

Correspondence to:

Dr Kazuhiro Kodama,

Department of

Neuropsychiatry, School of

Medicine, Chiba University,

1-8-1 Inohana, Chuo-ku,

Chiba, 260, Japan.

Received 10 February 1994

and in final revised form

2 September 1994.

Accepted for publication

9 September 1994 neuropsychiatric SLE who have no morphological changes. ${ }^{12-15}$ It has not, however, shown any pathological findings in patients without involvement of the CNS. There has been little research concerning the application of SPECT in patients with neuropsychiatric SLE, and there have been no reports investigating the significance of SPECT findings during the remission stage.

We performed SPECT with IMP on 20 patients with SLE, and obtained regional brain cerebral blood flow images. In this study, we examined the applicability of SPECT as a biological marker representing active cerebral involvement underlying psychiatric manifestations and the importance of cerebral blood flow findings during the remission stage of psychiatric events.

\section{Subjects and methods}

We examined 18 women and two men who fulfilled the criteria for SLE as revised in $1982 .{ }^{16}$ At the time of the first SPECT, the mean age was 31.8 (range $15-54$ ) years. The mean duration of the illness from the time of diagnosis was 53.9 (range 1-190) months. The average dosage of corticosteroids was $33.1 \mathrm{mg} /$ day (equivalent to prednisolone, except for one case under pulse treatment). There was clinical evidence or a history of psychiatric manifestations in 17 patients. Psychiatric events occurring before the first SPECT were paranoid-hallucinatory states (eight); depressive states (six); hypomanic states (three); encephalopathy (disturbance of consciousness; four), including plural psychiatric events in the same patients. There were only three patients without a history of psychiatric manifestations at the time of the first SPECT. Nineteen patients received corticosteroid treatment at the time of SPECT. Patients who had seizures, meningitis, and apparent focal neurological symptoms and signs were excluded.

SPECT was performed with a ZLC7500 system (Siemens) and IMP. A dose of 148 $\mathrm{MBq}$ was intravenously injected. The whole body radiation dose of IMP was $1.52 \mathrm{mGy}$. Scanning began 20 minutes after injection while the patients were resting with their eyes closed. Axial slices were in parallel with the orbitomeatal line. The thickness of each slice was $6 \mathrm{~mm}$. Coronal and sagittal images were also obtained. Regional cerebral blood flow from early images was examined by a 
radiologist and four psychiatrists separately and independently. A finding was deemed positive only when the five assessments classified it as such. Thirty one SPECT studies were performed from August 1988 to the end of January 1993. Informed consent was obtained for the SPECT studies from the patients themselves or their closest relatives.

Computed tomography was performed on all patients with either a GE8800 or a GE9800 at the same time as SPECT. All patients also underwent MRI at nearly the same time as the SPECT. The MRI machines used had a static magnetic field strength of 1.5 Tesla (Signa system, General Electric) and 0.5 Tesla (Vista-MR system, Picker International). An abnormal SPECT finding in the same region as a focal cerebral infarction diagnosed by MRI was not assessed as abnormal. A clear cerebral infarction diagnosed by MRI was confirmed in one patient (patient No 6, who had small brain infarction lesions in the right putamen and parietal lobe). Other abnormal MRI findings included small high signal areas in the white matter of nine patients. Computed tomography also showed slight cerebral atrophy in 14 patients

Figure 1 Patient No 5 (group A) $A 17$ year old woman was diagnosed as having SLE in fuly 1989 (fever, malar rush, nephritis, haemolytic anaemia,

hypocomplementaemia, and anti-DNA antibody). In September 1992 when she was thought to be in the relapsing stage of SLE because of malar rush, hypocomplementaemia, and increased anti-DNA antibody, psychiatric symptoms appeared (auditory hallucination, hearing voices and suicidal tendencies). The first SPECT was also performed at this time. It showed hypoperfusion in both frontal lobes and right hemisphere $(A)$. The second SPECT was

performed in November, at the time when the

psychiatric symptoms and cerebral blood flow findings had improved in a parallel manner (B). A third $S P E C T$, performed when psychiatric symptoms had returned, showed a recurrence of mild hypoperfusion in both frontal lobes (C). MRI was performed in October 1992 when she had psychiatric symptoms. Axial T2 weighted $M R I$ showed no abnormal finding other than mild atrophy in the cerebral hemispheres (D).

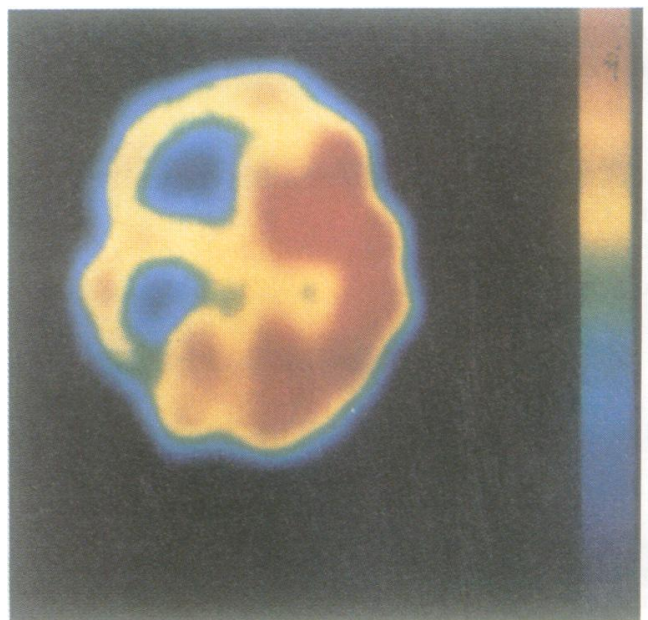

(A)

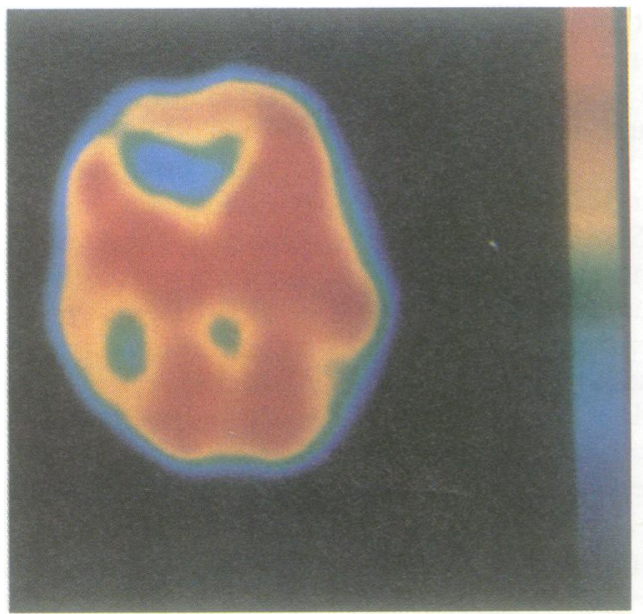

(C) (six with frontal atrophy, three with temporal atrophy, two with parietal atrophy, and three with diffused atrophy).

The diagnostic criteria of disease activity in SLE included fever, arthralgia, erythema, oral ulcer, alopecia, high erythrocyte sedimentation rate, hypocomplementaemia, leucopenia, hypoalbuminaemia, positive lupus erythematosus cell or test, and anti-DNA antibody. Patients were thought to have active disease when more than three of the diagnostic criteria applied. Only five patients showed SLE activity at the same time as the manifestation of psychiatric events.

The patients were divided into three groups and were investigated concerning the correlation between the change in psychiatric manifestations and the cerebral blood flow findings. Group A comprised nine patients (Nos 1-9) for whom SPECT was performed at the time of florid psychiatric events. Group B consisted of eight patients (Nos 10-17), for whom SPECT was performed at the time of remission of psychiatric manifestation. Group C comprised three patients who had no history of psychiatric events at the time the SPECT was performed.

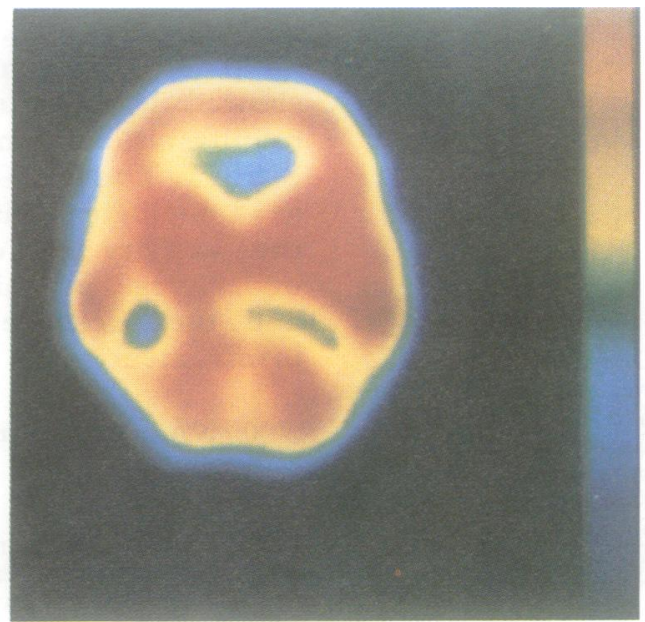

(B)

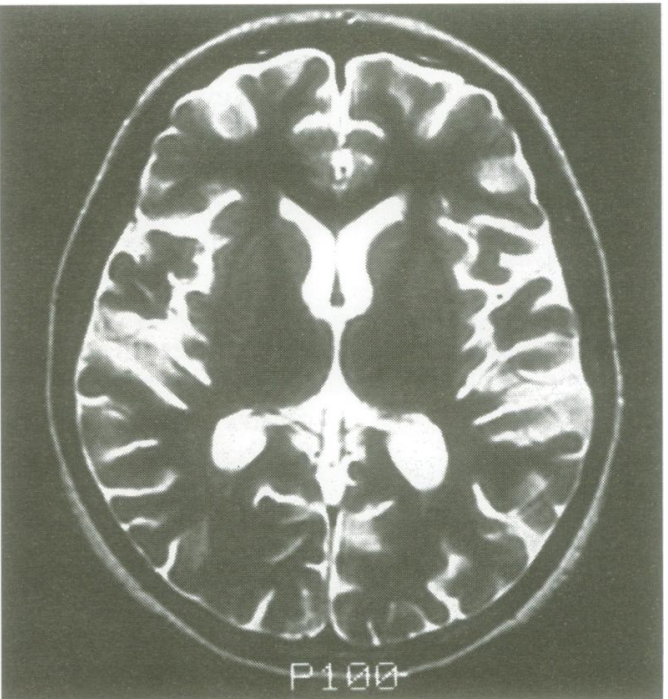

(D) 
Figure 2 Patient No 10 (Group B) $A 30$ year old woman was diagnosed with SLE in 1983 on the basis of depression, anti-DNA antibody, antinuclear antibody, and leucopenia. In 1984 and 1989 she became depressive, and in 1985 and 1987, manic. The first SPECT was performed in April 1991 during remission of the psychiatric events. It showed hypoperfusion in both frontal lobes $(A)$. In state of depression again. The second SPECT taken at this time showed severe hypoperfusion in both frontal lobes (B). In Fanuary 1993 a third SPECT performed when psychiatric symptoms had improved, showed an improvement in cerebral blood flow (C). MRI was performed in May 1992. Axial proton density weighted MRI at the level of anterior horns of the lateral ventricles showed mild atrophy in both frontal and temporal lobes and small high signal areas in the white matter (D). September she entered a

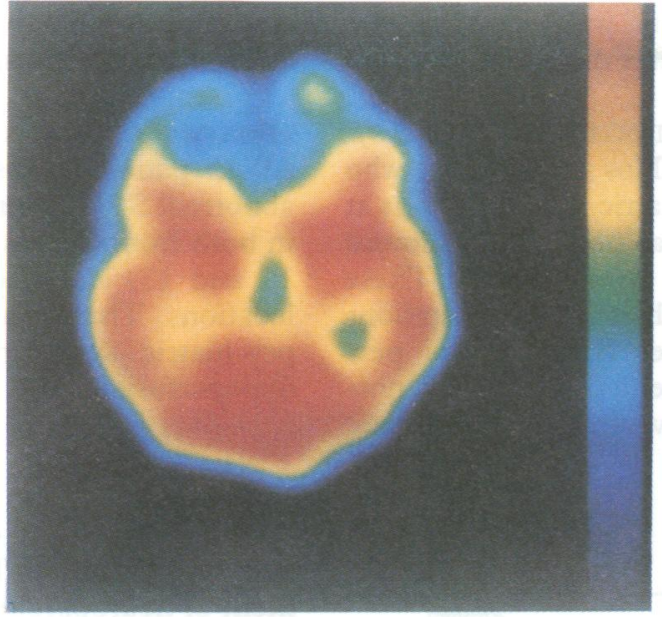

(A)

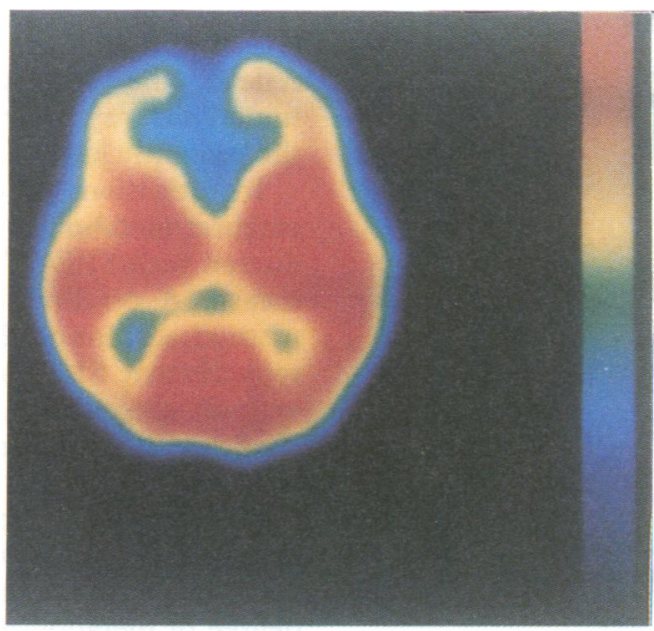

(C)

\section{Results}

SPECT FINDINGS (FIGS 1-3)

Fifteen of the 20 patients ( $75 \%$ ), had abnormal SPECT findings. All abnormal findings were bilateral frontal lobe hypoperfusion. All the patients who had SPECT at the time of florid psychiatric manifestations had abnormal SPECT findings. Only five patients had

Figure 3 Patient No 18 (group C) $A 15$ year old girl was diagnosed as having SLE on the basis of photosensitivity, malar rush, oral ulcers, antinuclear antibody, and anti-DNA antibody in April 1992. In Fune, when her condition had improved, a SPECT was performed. It showed hypoperfusion in both frontal lobes. After one month, she had disturbance of consciousness

(disorientation, memory loss, and short concentration span), but no change was found in the results of laboratory $C S F$ examination.

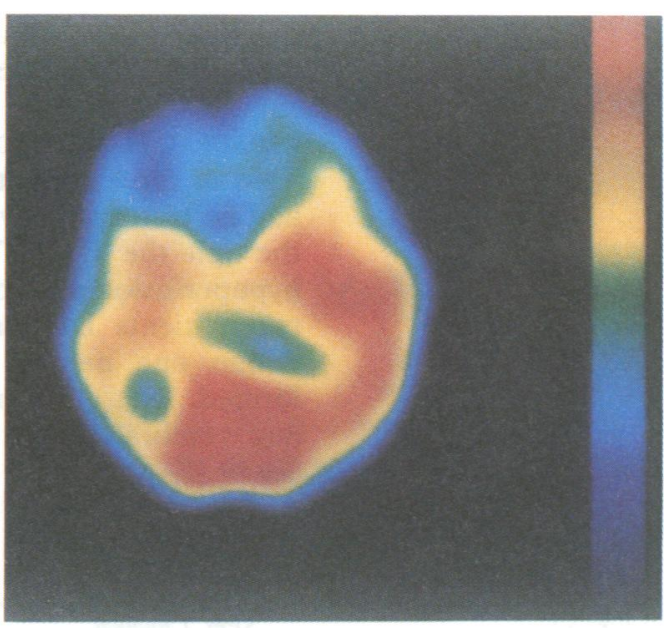

(B)

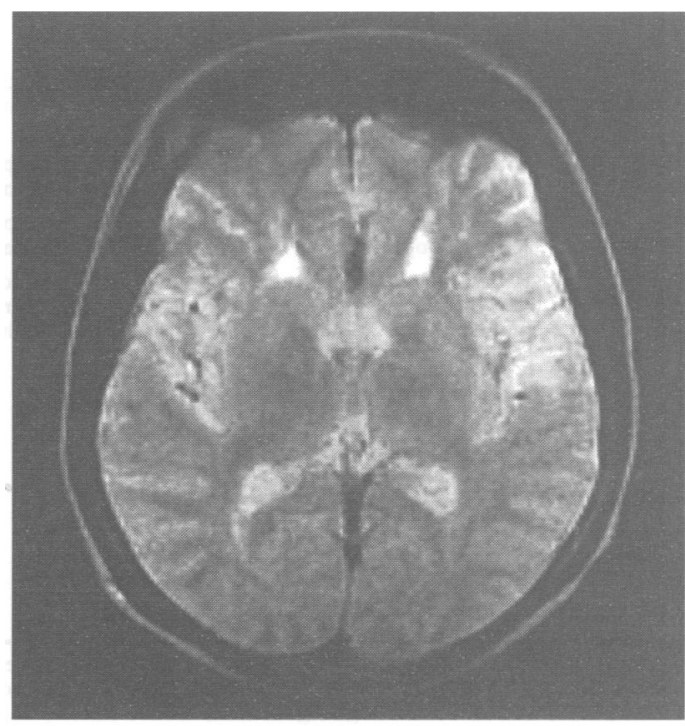

(D)

normal SPECT findings. These five had SPECT performed during remission of psychiatric symptoms or were those who had no history of psychiatric events.

CEREBRAL BLOOD FLOW FINDINGS IN GROUP A (TABLE 1)

All of the patients in group A had hypoperfusion. Five patients (Nos 1-5) had a second SPECT performed after improvement in psychiatric manifestations. In these five, the psychiatric symptoms and cerebral blood flow improved in a parallel manner.

CEREBRAL BLOOD FLOW IN GROUP B (TABLE 2) Four patients (Nos 10-13) had hypoperfusion, and the other four (Nos 14-17) had normal SPECT. Two patients (Nos 10 and 11), who had an exacerbation of psychiatric symptoms had a second SPECT, which showed more prominent cerebral blood flow findings parallel to the psychiatric exacerbation.

All four patients who had hypoperfusion had a psychiatric exacerbation one to six months after the SPECT.

Of the other four, who had no abnormal perfusion, the prognosis was good. No 
psychiatric exacerbation was reported for more than 18 months after the SPECT.

CEREBRAL BLOOD FLOW IN GROUP C (TABLE 3) Two of three patients (Nos 18 and 19), who had no history of psychiatric manifestations at the time the SPECT was performed, showed hypoperfusion in both frontal lobes. These two patients had psychiatric manifestations within one month after SPECT was performed. The other patient (No 20) had normal cerebral blood flow and no psychiatric

Table 1 SPECT findings (group $A$ )

\begin{tabular}{|c|c|c|c|c|}
\hline $\begin{array}{l}\text { Patient No } \\
\text { (sex/age) }\end{array}$ & & $\begin{array}{l}\text { SPECT findings } \\
\text { (clinical features) }\end{array}$ & & $\begin{array}{l}\text { Atrophy } \\
\text { (MRI findings) }\end{array}$ \\
\hline $\begin{array}{l}1 \\
(F / 34)\end{array}$ & $\begin{array}{l}\text { Bl-F and P } \\
\text { (paranoid- } \\
\text { hallucinatory state) }\end{array}$ & & $\begin{array}{l}\text { Improved } \\
\text { (remission) }\end{array}$ & $\overline{(-)}$ \\
\hline $\begin{array}{l}2 \\
(M / 37)\end{array}$ & $\begin{array}{l}\text { B1-F and lt-P } \\
\text { (paranoid- } \\
\text { hallucinatory state) }\end{array}$ & & $\begin{array}{l}\text { Improved } \\
\text { (remission) }\end{array}$ & $\stackrel{+}{(\mathrm{SHSA})}$ \\
\hline $\begin{array}{l}3 \\
(F / 27)\end{array}$ & $\begin{array}{l}\mathrm{Bl}-\mathrm{F}, \mathrm{rt}-\mathrm{T} \text { and } \mathrm{rt}-\mathrm{P} \\
\text { (manic state) }\end{array}$ & & $\begin{array}{l}\text { Improved } \\
\text { (remission) }\end{array}$ & $\begin{array}{l}+\mathrm{F} \\
\text { (SHSA) }\end{array}$ \\
\hline $\begin{array}{l}4 \\
(F / 35)\end{array}$ & $\begin{array}{l}\text { Bl-F and lt-P } \\
\text { (encephalopathy) }\end{array}$ & & $\begin{array}{l}\text { Improved } \\
\text { (remission) }\end{array}$ & $\begin{array}{l}+\mathrm{F} \\
\text { (SHSA) }\end{array}$ \\
\hline $\begin{array}{l}5 \\
(\mathrm{~F} / 17)\end{array}$ & $\begin{array}{l}\mathrm{Bl}-\mathrm{F} \text { and } \mathrm{rt}-\mathrm{H} \\
\text { (paranoid- } \\
\text { hallucinatory } \\
\text { state) }^{\star}\end{array}$ & $\begin{array}{l}\text { Improved } \\
\text { (improved) }\end{array}$ & $\begin{array}{l}\text { mild bl-F } \\
\text { (paranoid- } \\
\text { hallucinatory state) }\end{array}$ & $\begin{array}{l}+ \text { blt-H } \\
(-)\end{array}$ \\
\hline $\begin{array}{l}6 \\
(F / 54)\end{array}$ & & $\begin{array}{l}\mathrm{Bl}-\mathrm{F} \text { and rt-T } \\
\text { (paranoid- } \\
\text { hallucinatory state) }\end{array}$ & & $\begin{array}{l}+\mathrm{F} \\
\text { (cerebral } \\
\text { infarction) }\end{array}$ \\
\hline $\begin{array}{l}7 \\
(\mathrm{~F} / 47)\end{array}$ & & $\begin{array}{l}\mathrm{Bl}-\mathrm{F} \text { and } \mathrm{P} \\
\text { (encephalopathy) }^{\star}\end{array}$ & & $\overline{\text { (SHSA) }}$ \\
\hline $\begin{array}{l}8 \\
(F / 28)\end{array}$ & & $\begin{array}{l}\text { Bl-F } \\
\text { (depressive state) }^{\star}\end{array}$ & & $\begin{array}{c}+ \text { blt-H } \\
\text { (SHSA) }\end{array}$ \\
\hline $\begin{array}{l}9 \\
(F / 24)\end{array}$ & & $\begin{array}{l}\text { Bl-F } \\
\text { (depressive state) }\end{array}$ & & $\overline{-}$ \\
\hline
\end{tabular}

Group A patients for whom SPECT was performed at the time of florid psychiatric events. $\mathrm{Bl}=$ bilateral; $\mathrm{lt}=$ left; $\mathrm{rt}=$ right; $\mathrm{F}=$ frontal lobe; $\mathrm{T}=$ temporal lobe; $\mathrm{P}=$ parietal lobe; $\mathrm{H}=$ $\mathrm{Bl}=$ bilateral; $\mathrm{It}=$ left; $\mathrm{rt}=$ right; $\mathrm{F}=$ frontal lobe; $\mathrm{T}=$ temporal
hemisphere; $\mathrm{SHSA}=$ small high signal area; ${ }^{\star}$ active state of SLE

Table 2 SPECT findings (group B)

\begin{tabular}{|c|c|c|c|c|}
\hline $\begin{array}{l}\text { Patient No } \\
\text { (sex/age) }\end{array}$ & , & & $\begin{array}{l}\text { SPECT findings } \\
\text { (clinical features) }\end{array}$ & $\begin{array}{l}\text { Atrophy } \\
\text { (MRI findings) }\end{array}$ \\
\hline $\begin{array}{l}10 \\
(F / 30) \\
11 \\
(F / 37)\end{array}$ & $\begin{array}{l}\text { Bl-F } \\
\text { (remission) } \\
\text { Bl-F } \\
\left({ }^{\star} \text { remission) }\right.\end{array}$ & $\underset{(1 \text { month later })}{(5 \text { months later) }}$ & $\begin{array}{l}\begin{array}{l}\text { Severe Bl-F } \\
\text { (depressive state) }\end{array} \\
\begin{array}{l}\text { Bl-F and lt-T } \\
\text { (improved) }\end{array} \\
\text { (paranoid- } \\
\text { hallucinatory state) }\end{array}$ & $\begin{array}{l}+\mathrm{F} \text { and } \mathrm{T} \\
(\text { SHSA) } \\
+\mathrm{P} \\
(-)\end{array}$ \\
\hline $\begin{array}{l}12 \\
(\mathrm{~F} / 31) \\
13 \\
(\mathrm{~F} / 21) \\
14 \\
(\mathrm{~F} / 21) \\
15 \\
(\mathrm{~F} / 36) \\
16 \\
(\mathrm{~F} / 40) \\
17 \\
(\mathrm{M} / 26)\end{array}$ & $\begin{array}{l}\begin{array}{l}\text { Bl-F } \\
\text { (remission) }\end{array} \\
\begin{array}{l}\text { Bl-F and T } \\
\text { (remission) }\end{array} \\
\begin{array}{l}\text { Normal } \\
\text { (remission) }\end{array} \\
\begin{array}{l}\text { Normal } \\
\text { (remission) }\end{array} \\
\begin{array}{l}\text { Normal } \\
\text { (remission) }\end{array} \\
\begin{array}{l}\text { Normal } \\
\text { (remission) }\end{array}\end{array}$ & (3 months later) & $\begin{array}{l}\text { ND } \\
\text { (manic state) } \\
\text { ND } \\
\text { (encephalopathy) } \\
\text { Good PP } \\
\text { Good PP } \\
\text { Good PP } \\
\text { Good PP }\end{array}$ & $\begin{array}{l}+\mathrm{P} \\
(-) \\
+ \text { lt-T } \\
(-) \\
- \\
(-) \\
+ \text { bl-H } \\
(\text { SHSA }) \\
- \\
(-) \\
+ \text { F } \\
(-)\end{array}$ \\
\hline
\end{tabular}

Group B patients for whom SPECT was performed at the time of remission of psychiatric manifestations; ND = not done; $P P=$ psychiatric prognosis; other abbreviations as for table 1 .

Table 3 SPECT findings (group C)

\begin{tabular}{|c|c|c|c|c|}
\hline $\begin{array}{l}\text { Patient No } \\
\text { (sex/age) }\end{array}$ & & $\begin{array}{l}\text { SPECT findings } \\
\text { (clinical features) }\end{array}$ & & $\begin{array}{l}\text { Atrophy } \\
\text { (MRI findings) }\end{array}$ \\
\hline $\begin{array}{l}18 \\
(\mathrm{~F} / 15) \\
19 \\
(\mathrm{~F} / 48) \\
20 \\
(\mathrm{~F} / 28)\end{array}$ & $\begin{array}{l}\text { Bl-F } \\
\text { (normal) } \\
\text { Bl-F } \\
\text { (normal) } \\
\text { Normal } \\
\text { (normal) }\end{array}$ & 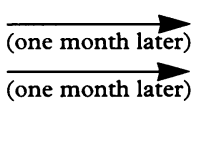 & $\begin{array}{l}\text { Encephalopathy } \\
\text { Encephalopathy }\end{array}$ & $\begin{array}{l}- \\
(-) \\
+\mathrm{F} \\
\text { (SHSA) } \\
- \\
(-)\end{array}$ \\
\hline
\end{tabular}

Group C = patients who had no history of psychiatric events at the time SPECT was performed. Abbreviations as for table 1 . manifestation for more than 18 months after SPECT was performed.

LOCATION OF ABNORMAL SPECT FINDINGS

All 15 patients (Nos 1-13, 18, and 19) with abnormal SPECT findings had hypoperfusion in both frontal lobes. Nine patients (Nos 1-7, 11 and 13) also had hypoperfusion in other locations. There was no correlation between psychiatric symptoms and the location of hypoperfusion.

\section{Discussion}

Patients with SLE often show neuropsychiatric symptoms. ${ }^{1-3}$ The diagnosis and treatment of neuropsychiatric SLE pose important problems. There are no crucial laboratory tests specific for the disease. The neuropsychiatric events are unpredictable and can occur at any time during the course of the disease, occasionally even preceding the onset of systemic disease. A biological marker that reflects the activity of CNS involvement underlying psychiatric symptoms, other than the presently known markers, is needed.

Investigations of cerebral blood flow and cerebral metabolism have recently been conducted with SPECT and PET. Pinching et al measured cerebral blood flow by the ${ }^{15} \mathrm{O}_{2}$ method and found that all patients with neuropsychiatric SLE had abnormal results, even without clinical signs of CNS involvement. ${ }^{17}$ Kushner et al reported changes in cerebral blood flow with the ${ }^{133} \mathrm{Xe}$ inhalation method paralleling the changes in neuropsychiatric symptoms. ${ }^{18}$ Volkow et al found that in patients with neuropsychiatric SLE, the degree of metabolism and blood flow impairment seemed to be correlated with the severity of the neuropsychiatric symptoms. ${ }^{13}$ Stoppe et al reported that all patients with neurological symptoms showed signs of pathological changes on PET, in accordance with the clinical state. ${ }^{14}$ Carbotte et al found that changes in cognitive profile in patients with neuropsychiatric SLE paralleled changes on PET. ${ }^{15}$ The patients who were included in PET studies by Stoppe et $a l^{14}$ and Carbotte et $a l^{15}$ were different from ours. Their patients had cerebral infarction, seizures, hemiparesis, and massive neuropsychological deficits. Kushner et al performed a SPECT with IMP on a patient with neuropsychiatric SLE, and reported that serial SPECT studies showed the resolution of multifocal cerebral perfusion defects that paralleled clinical recovery of the depressive state. ${ }^{11}$ The PET and SPECT procedures seem to be the most useful diagnostic methods for neuropsychiatric SLE. Pinching et al found that abnormalities in the regional distribution of oxygen utilisation and blood flow were present in 14 out of 15 patients with suspected neuropsychiatric SLE, and 10 out of 12 patients in whom CNS disease was not clinically apparent. ${ }^{17}$ Thus they inferred that ${ }^{15} \mathrm{O}_{2}$ brain scanning might prove valuable in the diagnosis of subclinical cerebral disease, but they used planar imaging and not CT. Their findings might be attributed to changes 
in blood flow in the scalp. There have been no reports about the relevance of SPECT or PET findings during remission.

Our present study showed that 15 of 20 patients $(75 \%)$ had abnormal cerebral blood flow. In particular, all nine patients in group A, for which SPECT was performed during florid psychiatric manifestations, showed abnormal SPECT results. In patients Nos $1-5$, who received a second SPECT, the psychiatric symptoms and cerebral blood flow improved in a parallel manner. For two patients in group B (Nos 10 and 11), the hypoperfusion became more evident in parallel with psychiatric exacerbation. Of the patients in groups A and B, only five had SLE activity. Concerning the correlation between the use of corticosteroids and cerebral blood flow findings, patient No 11, who had no corticosteroid treatment, showed hypoperfusion. It was reported that the dosage of corticosteroids and the duration of corticosteroid usage are not correlated with regional cerebral blood flow ${ }^{19}$; therefore, there is little possibility that the abnormal cerebral blood flow is based only on the influence of corticosteroids. Hypoperfusion on SPECT may therefore reflect the reversible changes in cerebral blood flow related to psychiatric manifestations and may be useful for diagnosis as a biological marker reflecting the psychiatric states.

We next investigated the correlation between cerebral blood flow and psychiatric prognosis. When patients with SLE and a history of psychiatric manifestations (group B) had abnormal SPECT findings during psychiatric remission, the SPECT findings seemed to represent the presence of subclinical CNS involvement, and indicated a poor psychiatric prognosis. Conversely, if the SPECT were normal, the psychiatric prognosis might be good. There were some patients (group C) who had abnormal SPECT findings with no history of psychiatric manifestations. These patients may have subclinical CNS involvement and would show psychiatric symptoms in the near future.

Our abnormal SPECT findings were reversible. They do not, therefore, only reflect the slight cerebral atrophy depicted by brain CT.

Repeat MRI was performed on some patients and there were no fundamental changes. Therefore, MRI may not be useful as a biological marker to predict psychiatric prognosis.

For patients with neuropsychiatric SLE, there was no specific correlation between clinical symptoms and the location of hypoperfusion or hypometabolism. Our present study showed that although all 15 patients with abnormal SPECT findings had hypoperfusion in both frontal lobes and nine of the 15 also had hypoperfusion in other areas, there was no specific correlation between psychiatric symptoms and the location of hypoperfusion.

Awada et al studied the regional cerebral blood flow of patients with SLE by the intravenous $^{133} \mathrm{Xe}$ method and reported that frontal hypoperfusion in those patients for which the interval between the last neurological or psychiatric event and cerebral blood flow measurement was greater than one year was more evident than in those who had episodes less than one year before cerebral blood flow measurement. ${ }^{19}$ It is worth emphasising that patients with SLE in psychiatric remission or with no history of psychiatric events who showed hypoperfusion, especially in the frontal lobes, later showed psychiatric manifestations. Frontal hypoperfusion or frontal hypometabolism has been reported in schizophrenia, depression, and dementia, and is not specific to a particular disease. The neuropsychological evaluation of frontal lobe function may be useful in elucidating the relevance of frontal hypoperfusion as shown by SPECT.

1 Johnson RT, Richardson EP. The neurological manifestations of systemic lupus erythematosus. Medicine 1968 47:337-69.

2 Estes D, Christian CL. The natural history of systemic lupus erythematosus by prospective analysis. Medicin 1971;50:85-95.

3 Ellis SG, Verity MA. The central nervous system involvement in systemic lupus erythematosus. A review of neuropathologic findings in 57 cases, 1955-1977. Semin Arthiritis Rheum 1979;8:212-21.

4 Gonzalez-Scarano F, Lisak RP, Bilaniuk LT, Zimmerman R, Atkins PC, Zweiman B. Cranial computed tomography in the diagnosis of systemic lupus erythematosus. Ann Neurol 1979;5:158-65.

5 Gaylis NB, Altman RD, Ostrov S, Quencer R. The selective value of computed tomography of the brain in cerebritis due to systemic lupus erythematosus. $f$ Rheumatol 1982;9:850-4.

6 Vermess M, Bernstein RM, Bydder GM, Steiner RE, Young IR, Hughes GRV. Nuclear magnetic resonance (NMR) imaging of the brain in systemic lupus erythematosus. F Comput Assist Tomogr 1983;7:461-7.

7 Aisen AM, Gabrielsen TO, McCune WJ. MR imaging of systemic lupus erythematosus involving the brain. $A \mathcal{F R}$ Am $\mathcal{F}$ Radiol 1985;144:1027-31.

8 Jacobs L, Kinkel PR, Costello RB, Alukal MK, Kinkel WR, Green FA. Central nervous system lupus erythematosus: the value of magnetic resonance imaging. $\mathcal{F}$ Rheumatol 1988;15:601-6.

9 McCune WJ, MacGuire A, Aisen A, Gebarski S. Identification of brain in neuropsychiatric systemic lupus erythematosus by magnetic resonance scanning. Arthritis Rheum 1988;31:159-66.

10 Sibbitt WL, Sibbitt RR, Griffey RH, Eckel C, Bankhurst $\mathrm{AD}$. Magnetic resonance and computed tomographic imaging in the evaluation of acute neuropsychiatric disease in systemic lupus erythematosus. Ann Rheum Dis 1989;48:1014-22.

11 Kushner MJ, Tobin M, Fazekas F, et al. Cerebral blood flow variations in CNS lupus. Neurology 1990;40: 99-102.

12 Hiraiwa $M$, Nonaka $C$, Abe $T$, Ito $M$. Positron emission tomography in systemic lupus erythematosus: relation of
cerebral vasculitis to PET findings. $A f N R A m \mathcal{F}$ cerebral vasculitis to $P$

13 Volkow ND, Warner N, Mcintyre R, et al. Cerebral involvement in systemic lupus erythematosus. $A m \tilde{J}$ Physiol Imaging 1988;3:91-8.

14 Stoppe G, Wildhagen K, Seidel JW, et al. Positron emission tomography in neuropsychiatric lupus erythematosus. Neurology 1990;40:304-8.

15 Carbotte RM, Denburg SD, Denburg JA, Nahmias C, Garnett ES. Fluctuating cognitive abnormalities and cerebral glucose metabolism in neuropsychiatric systemic lupus erythematosus. $f$ Neurol Neurosurg Psychiatry 1992;55:1054-9.

16 American Rheumatism Association subcommittee for SLE criteria. The 1982 revised criteria for the classification of SLE. Arthritis Rheum 1982;25:1271-7.

17 Pinching AJ, Travers RL, Hughes GRV, Jones T, Moss S Oxygen-15 brain scanning for detection of cerebral Oxygen-15 brain scanning for detection of cerebral involvement in

18 Kushner MJ, Chawluk J, Fazekas F, et al. Cerebral blood flow in systemic lupus erythematosus with or withou cerebral complications. Neurology 1987;37:1596-8.

19 Awada HH, Mamo HL, Luft AG, Ponsin JC, Kahn MF. Cerebral blood flow in systemic lupus erythematosus with and without central nervous system involvement. $\mathcal{F}$ Neurol Neurosurg Psychiatry 1987;50:1597-601. 